\title{
O uso da tecnologia na educação em meio à pandemia
}

\author{
The use of technology in education amid the pandemic
}

Gabriela Mousinho de Oliveira' ${ }^{1}$, Krâmio Sacramento de Melo ${ }^{1}$, Alan Victor Pereira do Nascimento $^{1}$, Talyson André Alves ${ }^{1}$, Alex Santos de Oliveira ${ }^{1}$, Landry Pereira da Silva ${ }^{1}$, Andrei Luiz Demétrio e Silva ${ }^{1}$, José Maria dos Santos Lobato Júnior ${ }^{1 *}$

\section{RESUMO}

O objetivo deste trabalho é mostrar formas de melhorar o ensino EaD (Educação à Distância) usando tecnologias, como os aplicativos de mensagem instantânea (Discord e Telegram) e suas potencialidades pedagógicas para o ensino remoto. Pela plataforma Google Forms, foi criado um questionário, com a proposta de obter informações das situações econômicas e sobre acesso à Internet com aparelhos de informática de qualidade dos discentes no período de pandemia com questões sobre inclusão digital e avaliação socioeconômicas dos discentes do IFPA campus Tucuruí. O Discord e o aplicativo Telegram se apresentaram como recursos eficazes para mediação remota, mas que sua integração estratégica no processo formativo demanda formação tecnológica dos professores e dos alunos.

Palavras-chave: Educação; Tecnologias; Ensino Remoto;

\begin{abstract}
The objective of this work is to show ways to improve distance education (Distance Education) using technologies such as instant messaging applications (Discord and Telegram) and their pedagogical potential for remote teaching. Through the Google Forms platform, an access was created, with the proposal to obtain information on the socioeconomic assessment of informatics and on the Internet with quality devices from students in the digital period and about the inclusion of students from the IFPA Tucuruí campus. Discord is based on technological training and the application for remote mediation, but on its strategic integration into the training process of teachers and students.
\end{abstract}

Keywords: Education; Technologies; Remote Teaching;

\footnotetext{
${ }^{1}$ IFPA - Instituto Federal de Educação, Ciência e Tecnologia - Campus Tucuruí

*E-mail: jose.lobato@ifpa.edu.br
} 


\section{INTRODUÇÃO}

As atividades escolares do ano letivo de 2020 nem bem começaram nas escolas brasileiras e de repente tivemos a interrupção das aulas presencias. O motivo foi o surgimento de uma doença causada pelo vírus SARS-CoV-2 (novo coronavírus) que é transmitida por meio do contato direto com uma pessoa infectada, ocasionando, assim, uma epidemia mundial. Milhares de professores, professoras e outros profissionais que atuam nas escolas, estudantes e suas famílias começaram a se fazer uma pergunta central: como levar o ensino adiante sem contrair esse novo vírus?

Wilder-Smith e Freedman (2020, p. 2) afirmam que o "distanciamento social e a quarentena foram projetados para reduzir, restringir a circulação e as interações entre pessoas". Esse distanciamento lança as bases para fortalecer o ensino mediado por tecnologias. As aplicações inovadoras possibilitaram novos paradigmas para produção de saberes por meio da utilização de ferramentas digitais e de interações sociais não presenciais.

Uma vez que os espaços educacionais presenciais estavam fechados, há uma demanda em aberto com relação à aprendizagem. Esse tema ocupa espaço nas discussões educacionais na atualidade, e a saída óbvia é a internet e os equipamentos a ela conectados. Mas o debate não se limita aos meios, mas avança para as questões do currículo e a necessidade de mudança de comportamento dos professores, das instituições e dos alunos. Nesse sentido, Almeida e Valente (2012) observam que a adaptação das tecnologias aos planos pedagógicos se constitui, mas que mídias, envolvem informações, relações culturais, linguagens, tempos e espaços. Essas abordagens geralmente apresentam tecnologias de comunicação como ferramentas que inovam práticas educativas, pois permitem maior flexibilidade nos métodos de aprendizagem (Andrade Carneiro, Prata, Moreira, \& Barbosa, 2019).

Para Almeida, Borges \& França (2012), é necessário que o sujeito saiba utilizar as tecnologias digitais uma vez que já fazem parte da nossa cultura e estão presentes no nosso cotidiano. Argumenta que, da mesma forma que adquirimos a tecnologia da escrita, é preciso, também, adquirir as tecnologias digitais, tendo em vista que elas possibilitarão a criação de novas formas de expressão e comunicação como, por exemplo: a criação e uso de imagens, sons, animação e a combinação dessas modalidades. 
O ensino em conjunto com a tecnologia pode aprimorar e desenvolver novos saberes uma vez que plataformas digitais de aprendizagem promovem a interatividade entre os indivíduos, permitindo que cada participante exponha ideias, compartilhe conhecimentos, habilidades e atitudes. Desta forma, essa modalidade é baseada na interação, permitindo que alunos acessem informações e sejam capazes de comunicar-se por meio do uso de dispositivos que acessem redes virtuais (SANTAELLA, 2013).

O objetivo deste trabalho é mostrar formas de melhorar o ensino EaD (Educação a Distância) usando tecnologias, como os aplicativos de mensagem instantânea (Discord e Telegram) e suas potencialidades pedagógicas para o ensino remoto, como resposta educacional à pandemia da COVID-19, fazendo uso das plataformas on-line e recursos educacionais para a continuidade do ensino em período de isolamento social. Ademais, verificamos as plataformas que melhor atende a esse ensino remote, tanto para os profissionais da educação quanto para os alunos. Também com o uso da plataforma Google Forms foi criado um questionário com questões sobre inclusão digital e avaliação socioeconômica dos participantes para saber a atual condição dos alunos e suas dificuldades.

\section{FUNDAMENTAÇÃO TEÓRICA}

Geralmente constitui duas ou mais disciplinas, com eles os autores buscam demonstrar aos leitores como aquela pesquisa se encaixa no campo de estudo e a parti de qual base será feita a análise dos dados.

\section{Matemática (Estatística)}

De acordo com a publcação de Luiz (s.d.) no site Brasil Escola

\footnotetext{
"A estatística é o campo da matemática que relaciona fatos e números em que há um conjunto de métodos que nos possibilita coletar dados e analisá-los, assim sendo possível realizar alguma interpretação deles". (LUIZ, s.d.)
}

Para a realização do projeto, esse conhecimento teórico foi utilizado para a coleta de dados e na realização da pesquisa. Com a coleta de dados, podemos fazer um levantamento de informações sobre a situação econômica dos estudantes.

\section{Metodologia Científica}

Coelho (2020) publicou no blog da mettzer garante que: 
"A metodologia científica é, um conjunto de procedimentos desse processo de investigação. Os procedimentos de investigação são os mecanismos de coleta e de análise de dados". (COELHO, 2020).

Por meio da organização do material coletado podemos utilizar de forma racional e sistemática, identificando a relação existente entre os dados e os fenômenos. E assim elaboramos as hipóteses; nessa terceira etapa o pesquisador deve elaborar perguntas a partir da proposta inicial, feita pela observação e a Conclusão do estudo.

No nosso projeto, utilizamos a metodologia científica para o estudo dos dados coletados.

\section{Sociologia (Classe Social)}

Segundo o artigo de Santos (2020) publicado no site Educa Mais Brasil:

"A Classe social é um conceito sociológico que remete à divisão de grupos que compartilham dos mesmos interesses e apresentam situação socioeconômica semelhantes". (SANTOS, 2020)

No nosso projeto, vemos as diferentes classes sociais e como isso pode impactar diretamente na educação e na qualidade de ensino.

\section{Geografia Econômica}

Lopes (2018) afirma em um artigo postado no site Educa Mais Brasil que

"A Geografia Econômica é o campo da Geografia Humana que estuda as transformações geográficas resultantes da localização, organização e distribuição das atividades econômicas. Ela visa compreender a maneira como o espaço geográfico e seus aspectos influenciam a economia e também o contrário, como a economia afeta o meio". (LOPES, 2018)

Com os impactos da pandemia causada pelo novo corona vírus, a situação socioeconômica acabou sendo afetada devida a crise que veio acompanhada com o a pandemia.

\section{METODOLOGIA}

Para atingir o objetivo proposto nesta pesquisa, utilizamos os seguintes procedimentos: pesquisa por meio de formulários eletrônicos na plataforma Google 
Forms $^{2}$ que continham questões sobre fatos e motivos comportamentais, além disso, fizemos uma análise descritiva dos dados, que são um conjunto de informações organizadas em tabelas e gráficos que visa descrever propensão de situações socioeconômicas e comportamentais. Esses dados são o resultado de características socioeconômicas e comportamentais de alunos do IFPA campus Tucuruí. Sendo que este método é destinado a organização e descrição de informações através de indicadores.

Para realizar a análise do uso de tecnologias educacionais para o ensino à distância no ensino técnico em período de pandemia da Covid-19, optamos pelo seguinte passo metodológico: levantamento e análise de dados referentes a inclusão digital e o processo socioeconômico de adesão pelos discentes do IFPA campus Tucuruí no ensino técnico e de graduação de tecnologias de ensino à distância. A proposta do uso destes instrumentos metodológicos é proporcionar uma reflexão mais aguçada das perspectivas para o uso de tecnologias de ensino à distância, considerando que no ambiente criado pela pandemia da Covid-19, estas questões se tornam mais desafiadoras.

Foram levantados dados sobre inclusão digital e avaliação socioeconômicas dos discentes do curso de Manutenção e Suporte em Informática e Superior do curso Informática do IFPA campus Tucuruí - tais como acesso à internet, tipos de conexão (banda fixa ou móvel), posse de equipamentos de tecnologia da informação (celulares, computadores, tablets), responsabilidades sobre as pendências, classe econômica. Estes dados foram coletados do formulário eletrônico disponibilizado no dia 29/09 até 11/10 de 2021. A análise dos dados levantados com a pesquisa buscou relacionar de forma descritiva como o desempenho escolar no período de pandemia pode ter caído ou aumentado devido os fatores de acesso à internet e de distribuição de renda.

Por fim, os dados foram sistematizados de maneira simples para compreender o fenômeno, os quais buscaram atender os objetivos desta pesquisa, obtivemos os resultados de como os discentes com condições socioeconômicas afetadas pela Covid-19, direta ou indiretamente tiveram seu aprendizado melhorado.

\footnotetext{
${ }^{2}$ O Google Forms é um serviço que tem por objetivo facilitar a criação de formulários e questionários diversos. Disponível gratuitamente para todos que possuírem uma conta Google, o serviço pode ser acessado em diversas plataformas, como web, desktop e celular. Ele é útil para todos aqueles que queiram fazer um formulário de pesquisa ou de coleta de opiniões.
} 


\section{O Discord como uma ferramenta de estudo EaD}

Discord é o aplicativo que selecionamos pra cuidar tanto da parte de vídeo conferências quanto pra chat de grupos de estudos (WhatsApp muito utilizado nesse quesito).

O Discord foi lançado em 13 de maio de 2015 como um concorrente da plataforma Skype que fazia muito sucesso na época. O Discord é uma plataforma de comunicação instantânea, em que você pode trocar mensagens de áudio, texto e vídeo, disponível tanto para PCs quanto para Smartphones. Nele, pode-se criar um servidor que englobará vários grupos, e dentro desses grupos ficam os canais de textos ou voz.

Uma de suas maiores vantagens é a união entre um sistema de mensagens instantâneas com o envio de fotos, arquivos e ao mesmo tempo um sistema de transmissão ao vivo, pegando o melhor dos dois mundos.

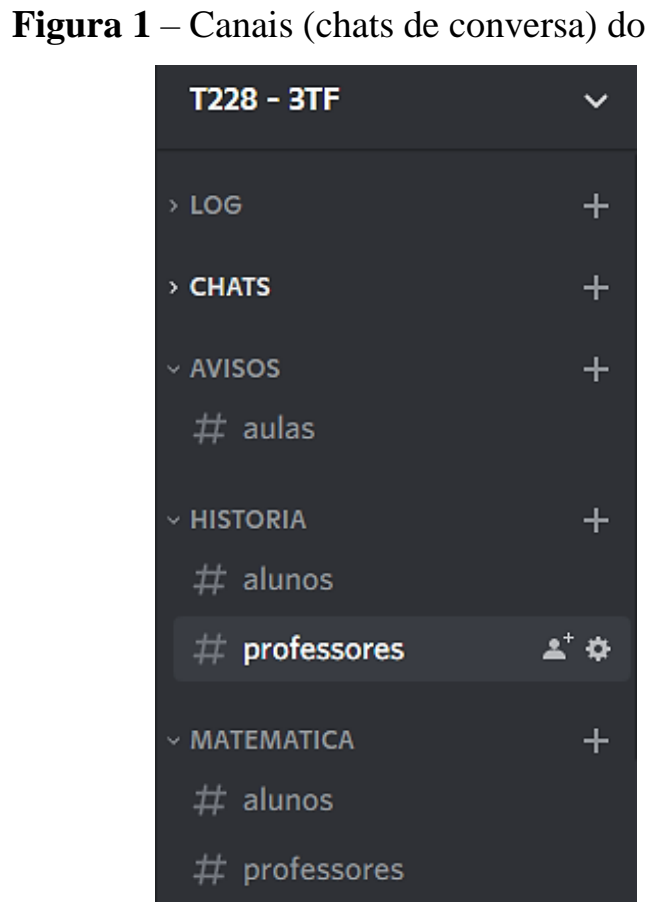

Fonte: Os autores (2021)

O Discord também é utilizado para a criação de um servidor com o aglomerado de todas as matérias em um só lugar, onde, com outros aplicativos, seria necessário a criação de cada grupo para cada disciplina separadamente. 
Figura 2 - Chat (dos professores) de aviso sobre aulas dos alunos

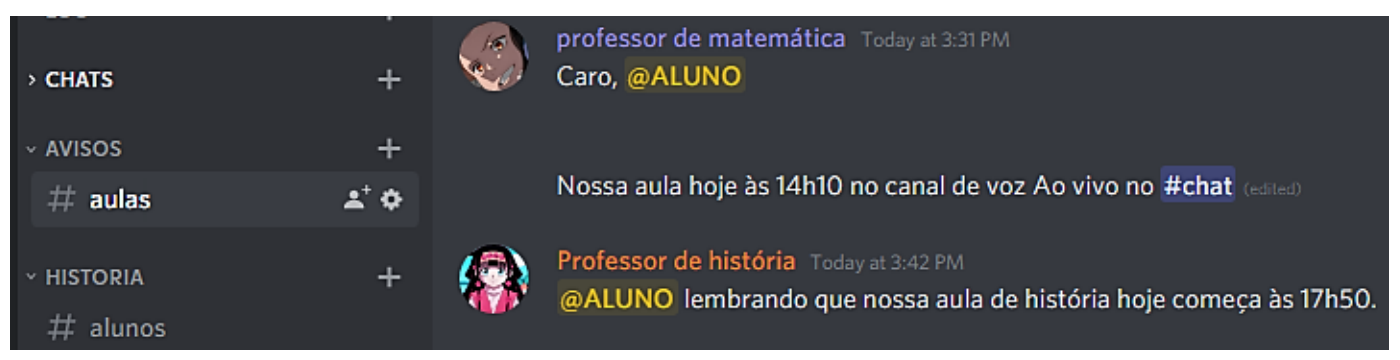

Fonte: Os autores (2021)

Uma exclusividade do Discord é o uso de cargos, onde cada usuário poderá ter um cargo, e assim que ele for marcado o usuário com o respectivo cargo será notificado/mencinado. Assim sendo, professores poderão marcar alunos para notificar de avisos.

Figura 3 - Chat dos alunos

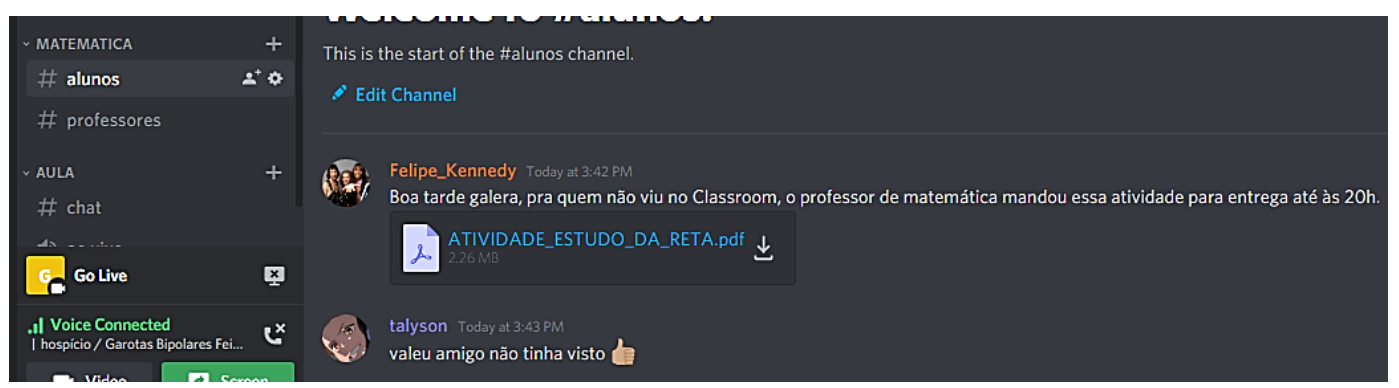

Fonte: Os autores (2021)

Figura 4 - Transmissão ao vivo

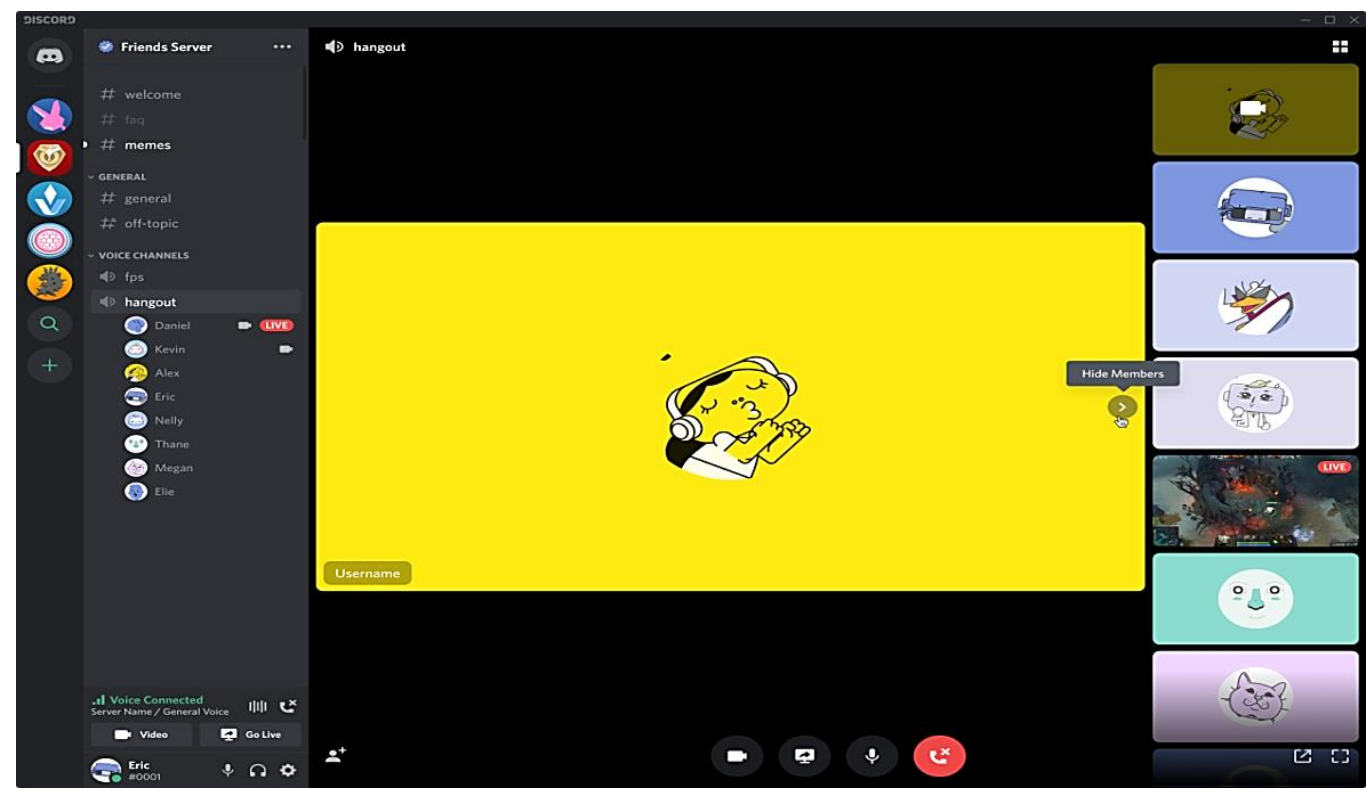

Fonte: https://support.discord.com/hc/pt-br/articles/360041721052-Chamadas-de$\mathrm{V} \% \mathrm{C} 3 \%$ ADdeo 
Como todo e qualquer aplicativo de mensagens, é possível o envio de fotos, arquivos, áudio e vídeos (com limite de tamanho restritivo para $8 \mathrm{MB}$ ) em seus canais de interação.

Figura 5 - Chat de conversa da aula ao vivo

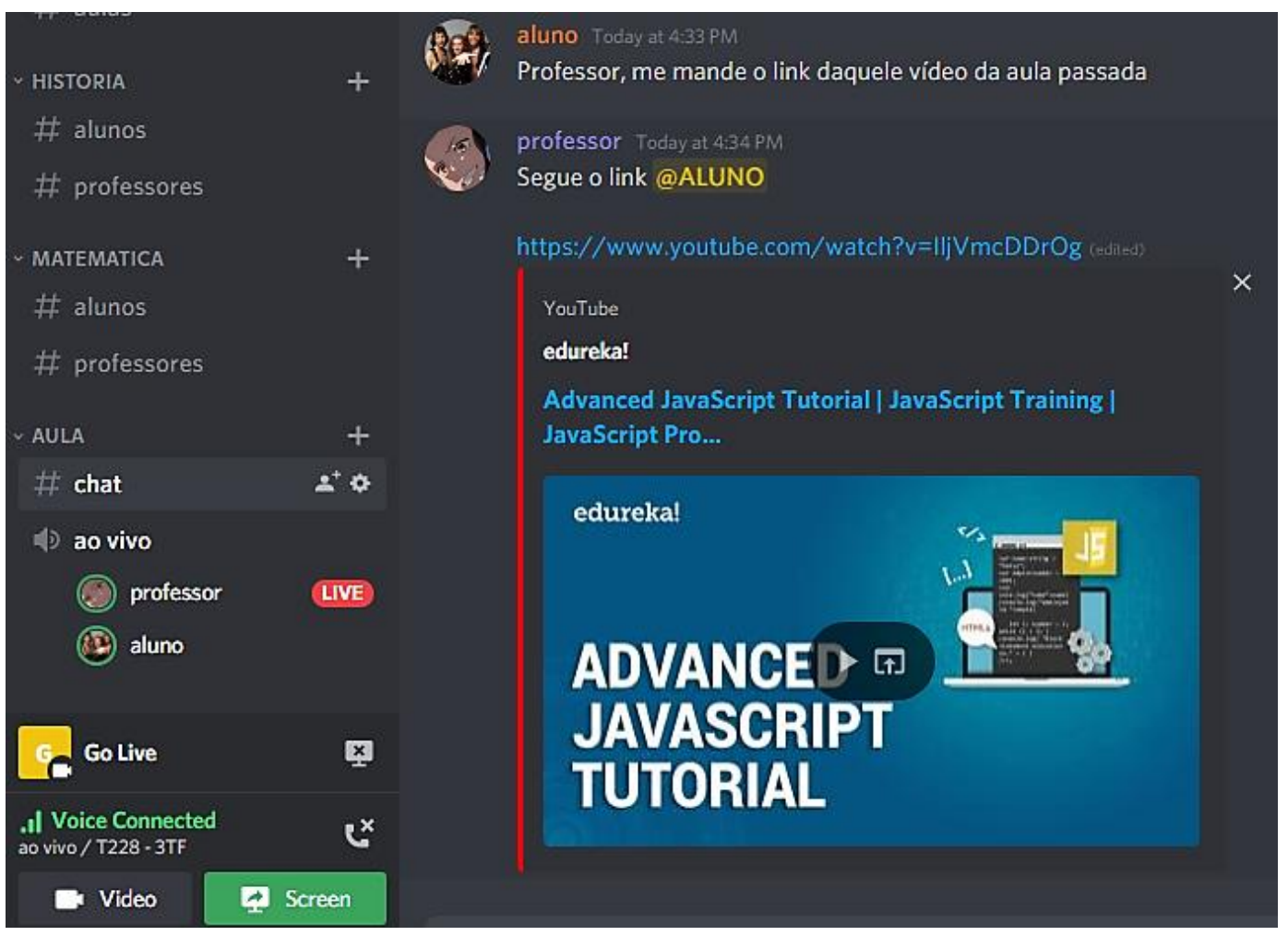

Fonte: Os autores (2021)

O aplicativo supracitado oportuniza chamadas de vídeo, com limite para 25 telas simultâneas, sem limite pré-determinado. Com os chats para envio de mensagens, as aulas tornam-se muito mais interativas e dinâmicas, tanto para o aluno quanto para o professor. Além disso, caso queiramos enviar um link de algum vídeo visto na aula é só rolar, procurar e mandar no chat desejado, uma vez que as transmissões são feitas na mesma plataforma.

A facilidade de login também é um ponto importante a considerar, pois o usuário só precisa de um e-mail e uma senha para logar com internet.

Sabemos que o WhatsApp Web só funciona se você estiver com o celular conectado à internet, a partir do momento em que o smartphone esteja offline ele desconecta do computador, coisa que não acontece com o Discord e um de seus próprios concorrentes diretos, o Telegram. 


\section{Telegram como uma ferramenta de estudo EaD}

O Telegram é um serviço de mensagens instantâneas baseado na nuvem está disponível para smartphones ou tablets, computadores e também como Aplicação Web. Os usuários podem fazer chamadas com vídeo, enviar mensagens e trocar fotos, vídeos, autocolantes e arquivos de qualquer tipo.

Figura 6 - Página inicial Telegram

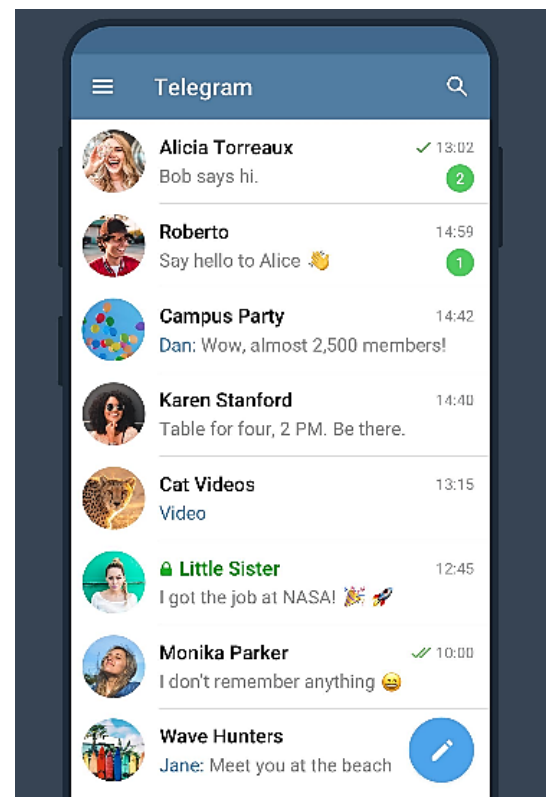

Fonte: https://telegram.org

O Telegram é um tipo de mensageiro concorrente direto do WhatsApp. Mas pouco popular entre os usuários, mesmo possuindo muitos recursos interessantes e por ser bem fácil e rápido de usar, ele até é considerado melhor que o WhatsApp pelos usuários.

O WhatsApp pode ser usado no navegador Web, mas temos que concordar que é de maneira limitada, pois precisa do smartphone ou tablet para que tenha o aplicativo, enquanto isso, você pode usar o Telegram no Smartphone, Tablet, navegador e até em seu computador/notebook com possibilidade de usar mais de uma conta no mesmo aplicativo/site.

O melhor é que nada disso exige muito do usuário, bastando apenas baixar o app correspondente para cada plataforma, fazer login com sua conta e começar a aproveitar o serviço. É lógico que isso o torna muito mais seguro e estável.

Os grupos no Telegram podem ser enormes, com até 200 mil membros no mesmo grupo (figura 7). 
Figura 7 - Chat de conversa do Telegram

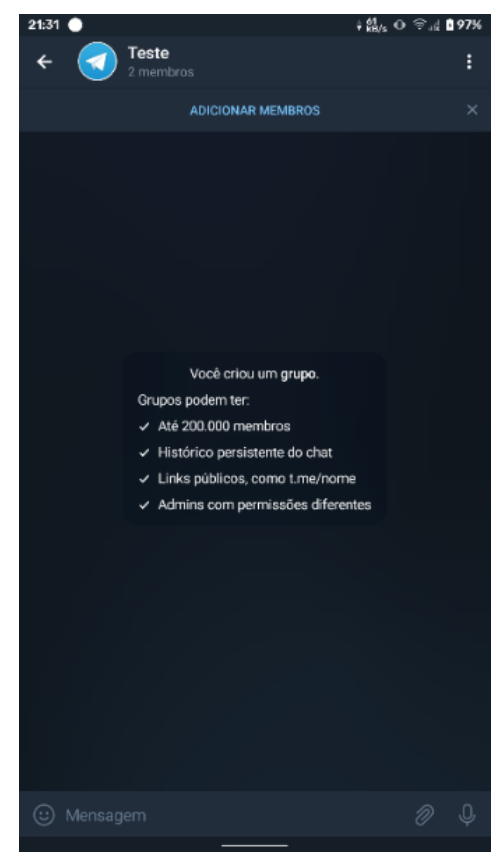

Fonte: Os autores (2021)

E com opção de ver as mensagens que foram enviadas antes de você entrar no grupo (figura 8), além de outras várias funções internas do grupo como limitar o envio de mensagens e permitir ou não permitir o envio de mensagem, Mídias, Stickers, Gifs, Enquetes, Links, entre outros mostrado na figura 9.

Figura 8 - Histórico de mensagens/arquivos

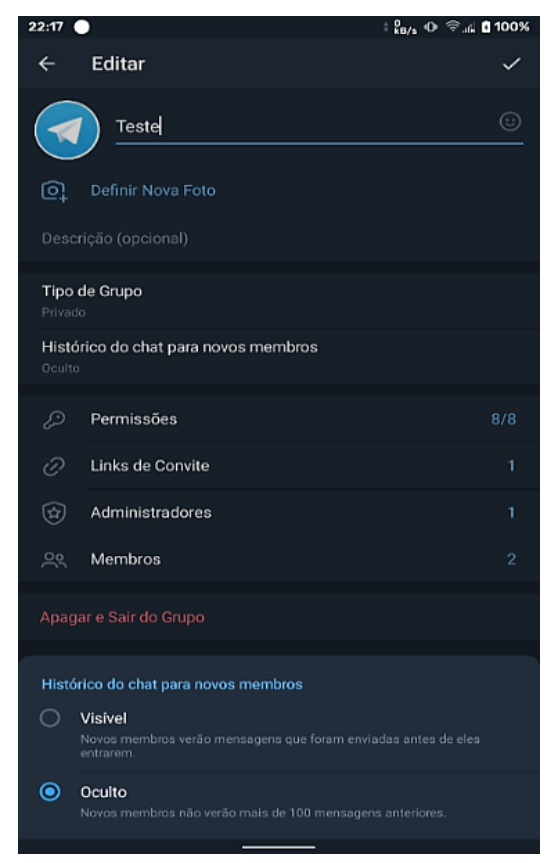

Fonte: Os autores (2021) 
Figura 9 - Permissões do grupo

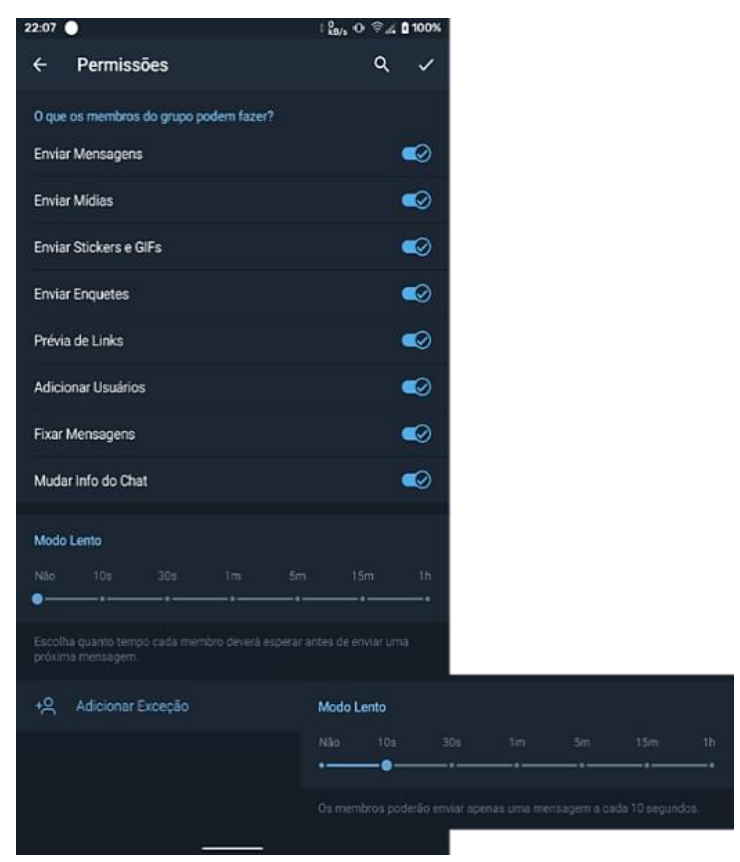

Fonte: Os autores (2021)

É bem comum compartilhar arquivos no WhatsApp com seus amigos, como fotos, vídeos, documentos e áudios, por exemplo. Mas o app ainda impõe muitas limitações quanto os tipos de mídia e o tamanho dos arquivos enviados nos chats. Isso não se repete no Telegram, que suporta qualquer formato de mídia e permite o compartilhamento de arquivos de até 2 GB por arquivo (Dados de Julho de 2021).

Além dos recursos citados, segundo a Analista de Marketing da DINO esclarece que o Telegram possui centenas de boots para os mais diversos fins, como leitura de emails (Gmail) e pesquisas no Google, além de conversão de arquivos (DINO, 2020).

\section{RESULTADOS}

No Brasil um ponto relevante verificado durante a pandemia é a falta de treinamento e experiência no uso de plataformas digitais como forma de aprendizagem. (OLIVEIRA, 2020)

De acordo com a nossa pesquisa verificamos que a maior parte dos alunos entrevistados não está satisfeita com as aulas no format online por vários motivos, dos quais os principais são: a falta de preparo/equipamentos para serem utilizados e não ter um ambiente apropriado para acompanhar as aulas, trazendo como consequência distrações frequentes. 
Figura 10 - Imagem contendo o resultado de pesquisa usando o recurso a paltaforma Google Forms

\section{Contagem de Qual você considera melhor para seu aprendizado?}

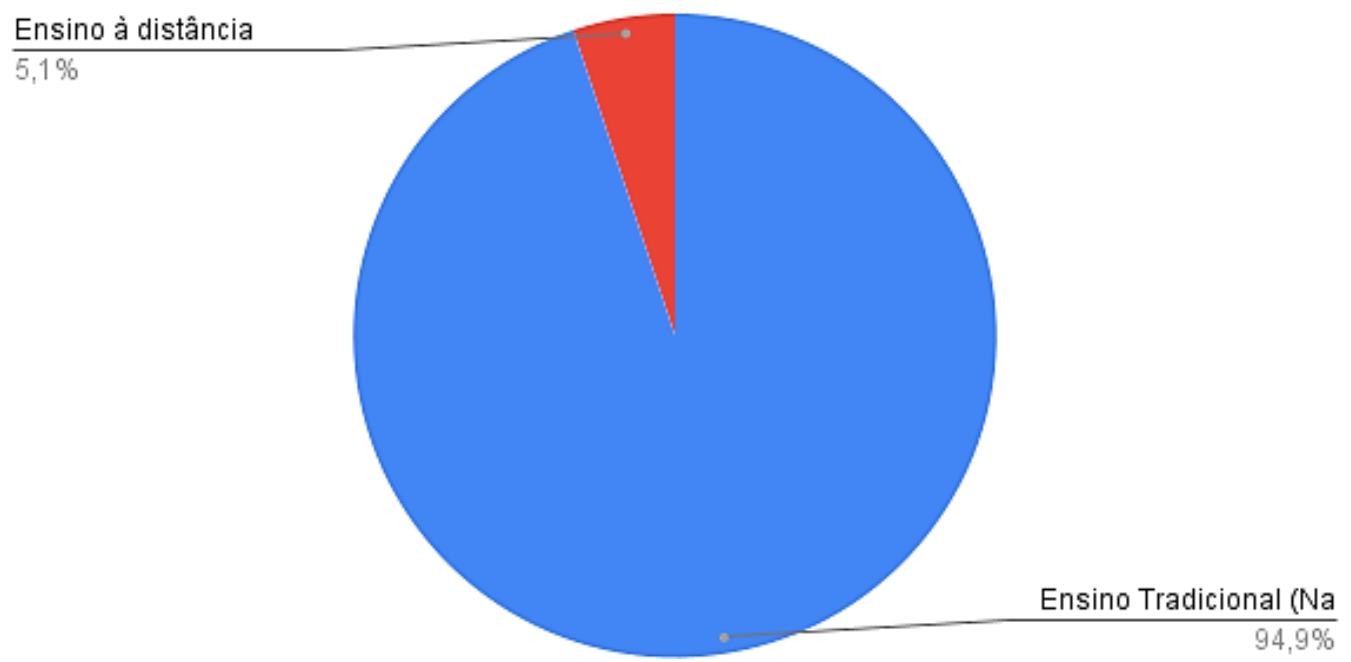

Fonte: Os autores (2021)

Para se ter uma ideia de comparação, em uma pesquisa levantada pelo campus IFPA Tucuruí, usando a mesma metodologia de pesquisa com o Google Forms, realizada entre 17/07 e 25/07 de 2020, onde, no total, foram entrevistados 600 alunos, a dificuldade do uso de ferramentas do ensino remoto se mantém.

Quadro 1 - Declaração dos alunos sobre as habilidades pessoais em utilizar a internet

\begin{tabular}{|l|c|c|}
\hline \multicolumn{1}{|c|}{ Nível de habilidade } & $\begin{array}{c}\text { Quantidade } \\
\text { de docentes }\end{array}$ & $\begin{array}{c}\% \text { do } \\
\text { total }\end{array}$ \\
\hline NÃO TENHO DIFICULDADE em utilizar a internet. & 278 & $46 \%$ \\
\hline $\begin{array}{l}\text { NÃO TENHO muitas dificuldades em utilizar internet, mas de vez em quando } \\
\text { preciso de alguma orientação. }\end{array}$ & 293 & $49 \%$ \\
\hline $\begin{array}{l}\text { TENHO muitas dificuldades em utilizar a internet, preciso de muita orientação } \\
\text { e acompanhamento. }\end{array}$ & 29 & $5 \%$ \\
\hline TOTAL & 600 & $100 \%$ \\
\hline
\end{tabular}

Fonte: CERAE, IFPA-TUCURUÍ (2020)

Entre os docentes do campus Tucuruí, onde 58 responderam ao questionário, mostram que eles estão interessados em introduzir ferramentas em suas estratégias de ensino remoto. (Quadro 2)

Quadro 2 - Interesse dos docentes em introduzir ferramentas digitais e remotas no processo de ensino 


\begin{tabular}{|l|c|c|}
\hline \multicolumn{1}{|c|}{ Interesse } & $\begin{array}{c}\text { Quantidade } \\
\text { de docentes }\end{array}$ & $\begin{array}{c}\% \text { do } \\
\text { total }\end{array}$ \\
\hline Tenho interesse. & 26 & $37,70 \%$ \\
\hline Tenho interesse, mas não conheço as condições de adaptação dos meus alunos. & 33 & $47,80 \%$ \\
\hline Tenho interesse e sei que meus alunos podem se adaptar. & 15 & $21,70 \%$ \\
\hline $\begin{array}{l}\text { Tenho interece, mas muitas dificuldades técnicas em utilizar a internet, preciso } \\
\text { de muita orientação e acompanhamento. }\end{array}$ & 13 & $18,80 \%$ \\
\hline $\begin{array}{l}\text { Tenho interesse e não tenho muitas dificuldades técnicas em utilizar a internet, } \\
\text { mas de vez em quando preciso de alguma orientação especializada. }\end{array}$ & 12 & $17,40 \%$ \\
\hline Tenho interesse, mas minha disciplina não é adaptável ao contexto remoto & 6 & $8,70 \%$ \\
\hline
\end{tabular}

\section{Fonte: CERAE, IFPA-TUCURUÍ (2020)}

Quadro 3 - Ferramentas e atividades digitais já utilizados pelos docents

\begin{tabular}{|l|c|c|}
\hline \multicolumn{1}{|c|}{ Ferramentas e/ou Atividades Digitais } & $\begin{array}{c}\text { Quantidade } \\
\text { de docentes }\end{array}$ & $\%$ do total \\
\hline Telegram/Whatsapp/Viber. & 41 & $70,7 \%$ \\
\hline Netflix/Youtube/Streaming. & 37 & $53,6 \%$ \\
\hline Mconf da RNP/Google Meet. & 28 & $40,6 \%$ \\
\hline AVA (Ambiente Virtual de Aprendizagem) MS Teans/Google Classrom. & 18 & $26,1 \%$ \\
\hline Quinzes/Games. & 14 & $20,3 \%$ \\
\hline Facebook/Instagram/Twitter. & 9 & $13,0 \%$ \\
\hline Outras ferramentas ou atividades. & 3 & $4,2 \%$ \\
\hline Nunca utilizei ferramentas digitais. & 2 & $2,8 \%$ \\
\hline
\end{tabular}

Fonte: CERAE, IFPA-TUCURUÍ (2020)

Com esses dados extras, percebe-se um interesse por parte dos professores de usar ferramentas para melhorar a aprendizagem e o ensino das atividades remotas, mas tanto os docentes quanto os discentes tem dificuldades de usá-las. Essa dificuldade pode ser por falta de afinidade com a tecnologia ou a própria ferramenta utilizada pelos mesmos não possui uma finalidade e não tem suporte ou a falta de funcionalidades para atividades acadêmicas. A falta de domínio dessas ferramentas, que não são apropriadas para o ensino, dificulta a aprendizagem do aluno.

Outro ponto importante do levantamento são os dados sobre os tipos de conexão. Porém, visto que a internet com maior velocidade em regra obtida a partir de redes de banda larga fixa, são mais presentes nas regiões mais desenvolvidas do país (Sul e Sudeste) e nas classes mais ricas. O tipo de internet mais utilizada pelas entidades do Instituto Federal do Pará - Campus Tucuruí feita nas turmas de manutenção $2^{\circ}$ e $3^{\circ}$ juntos ao curso subsequente de informática está nos gráficos abaixo.

Figura 11 - Dados do formulário sobre o tipo de internet 
Contagem de Qual(is) $0(s)$ tipo(s) de acesso a internet que você utilizar em sua residência? (Pode marcar mais de uma alternativa).

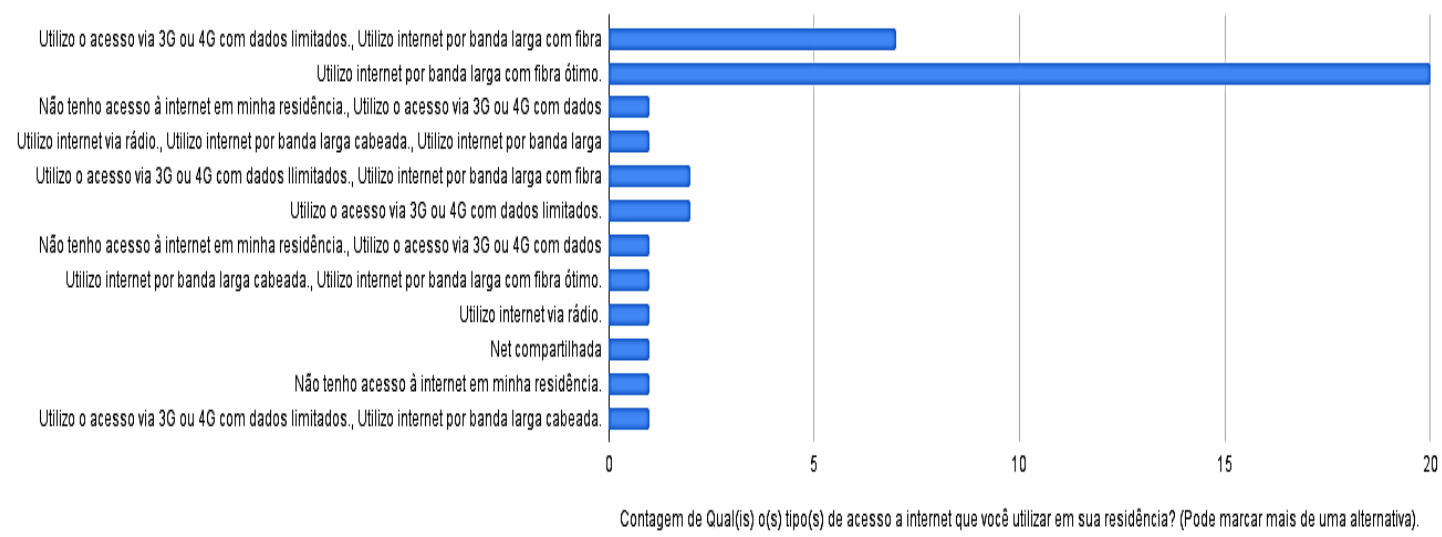

Fonte: Os autores (2021)

Figura 12 - Dados do formulário sobre a velocidade de internet

Qual a velocidade da internet banda larga que você utiliza?

39 respostas

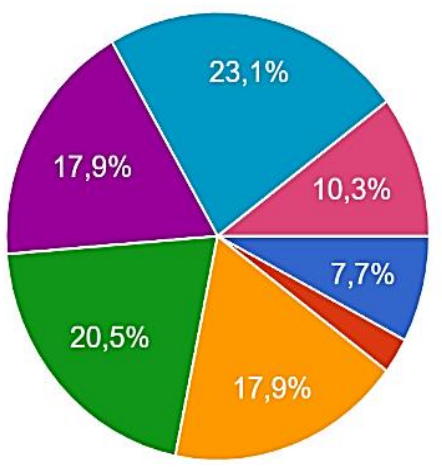

Não tenho internet banda larga.

Inferior a $1 \mathrm{Mbps}$.

Entre 1,1 a $10 \mathrm{Mbps}$.

Entre 10 e 50 Mbps.

Entre 50 e $100 \mathrm{Mbps}$

Superior a 100 Mbps.

Não sei dizer no momento.

Fonte: Os autores (2021)

De acordo com a figura 17 e 18 a maioria dos entrevistados utilizam internet fibra ótica ou internet de operadora limitada, e 51,3\% com velocidade igual ou superior à 50 mbps, uma velocidade boa, mas nem todos tem essa oportunidade como conta os outros $48,7 \%$ com internet inferior a 50 mbps.

O IBGE destaca ainda que o telefone celular continua sendo a principal ferramenta utilizada pelos conectados (IBGE, 2021). Os aparelhos celulares foram encontrados em maiores números dos entrevistados (figura 13).

Figura 13 - Tipos de dispositivos usados pelos entrevistados 


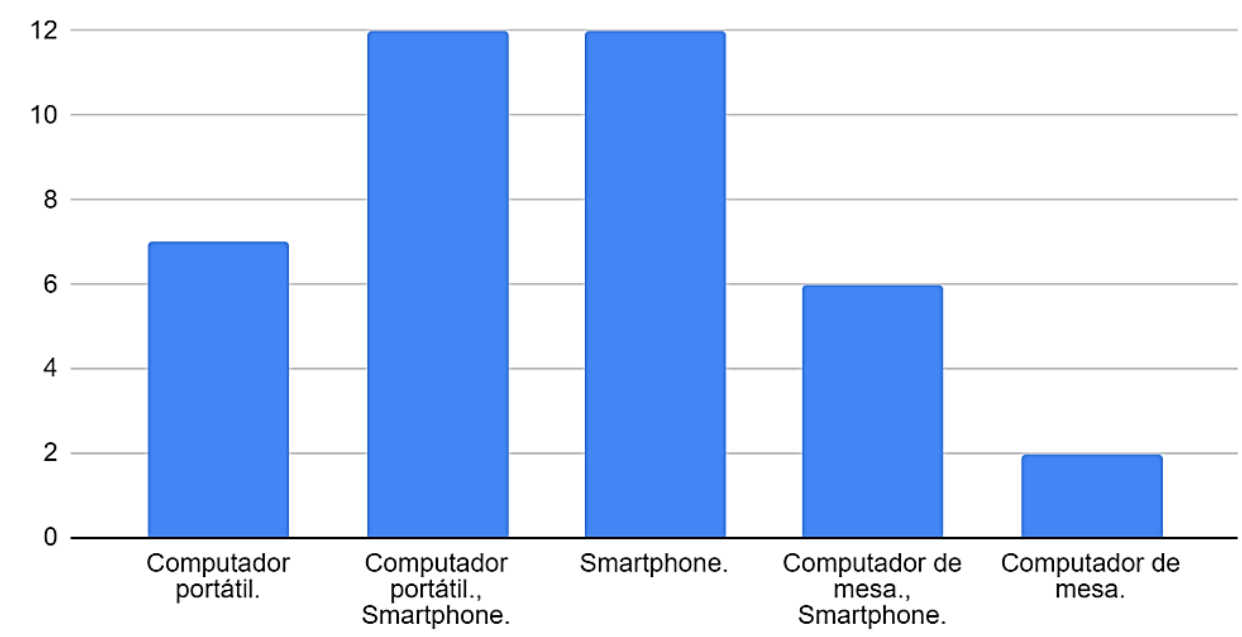

Fonte: Os autores (2021)

Todos os participantes da pesquisa têm algum tipo de dispositivo que possa assistir as aulas $\mathrm{EaD}$ ou fazer pesquisas, foi um resultado satisfatório todos terem, mas o resultado pode sofrer alteração se for contar o total de alunos que não tiveram a oportunidade de responder por falta de algum dispositivo.

$\mathrm{Na}$ avaliação percebemos que muitos dos pesquisados não conseguiram/conseguem aprende de forma eficaz com as dificuldades que foram encontradas ao decorrer dos estudos na quarentena (figura 14).

Figura 14 - Aprendizagem da matriz curricular

Contagem de Em relação ao curso, você aprendeu os assuntos da matriz curricular?

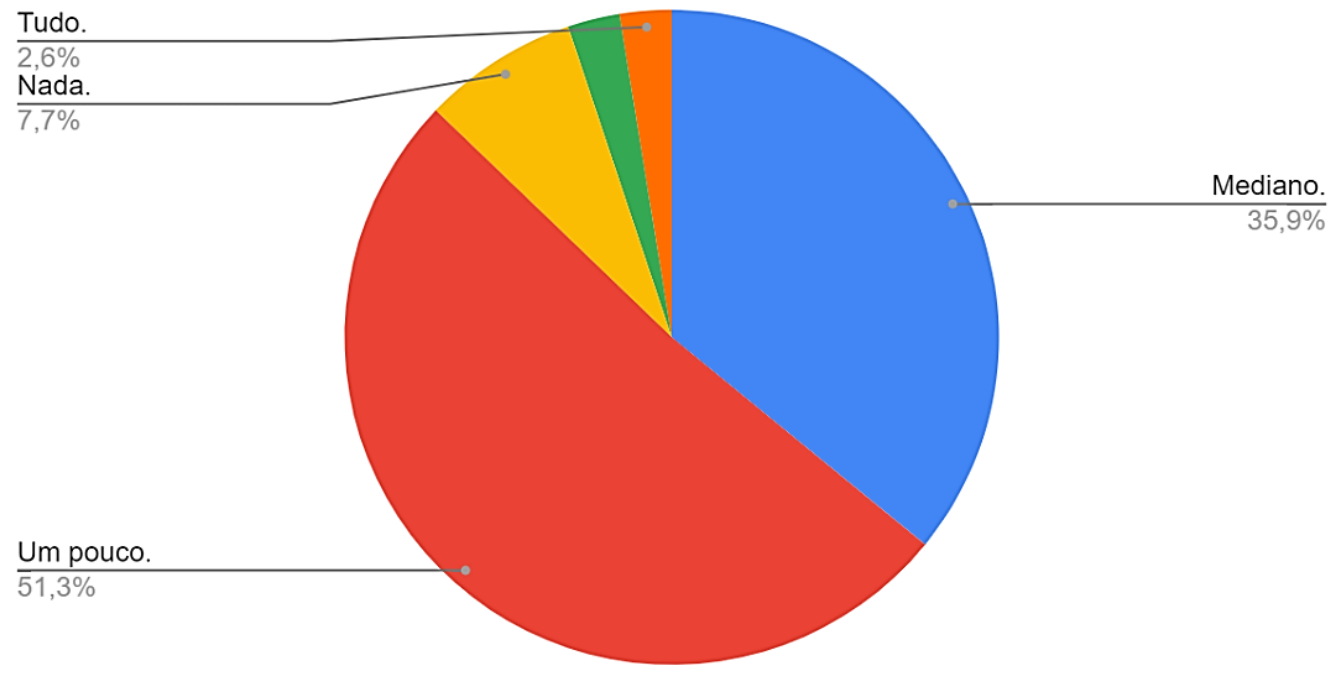

Fonte: Os autores (2021)

Figura 15 - Eficácia dos professores (opinião dos alunos entrevistados) 


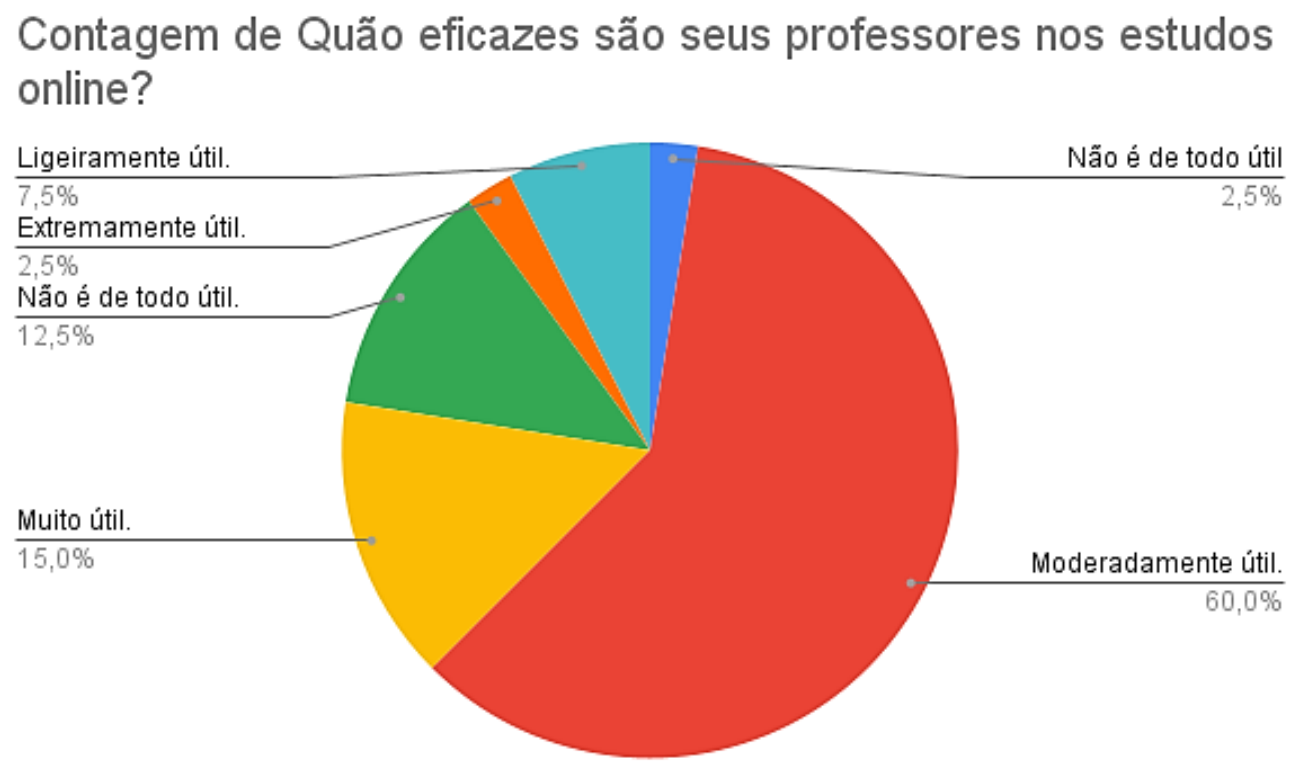

Fonte: Os autores (2021)

Mesmo com várias dificuldades os que conseguiram ter continuidade nos estudos durante a pandemia, esforçam para conseguir ter um bom desempenho e não ter problemas com as notas. Cerda de $74,4 \%$ está usando técnicas de estudos para complementar no aprendizado.

Figura 16 - Usam técnicas de estudo

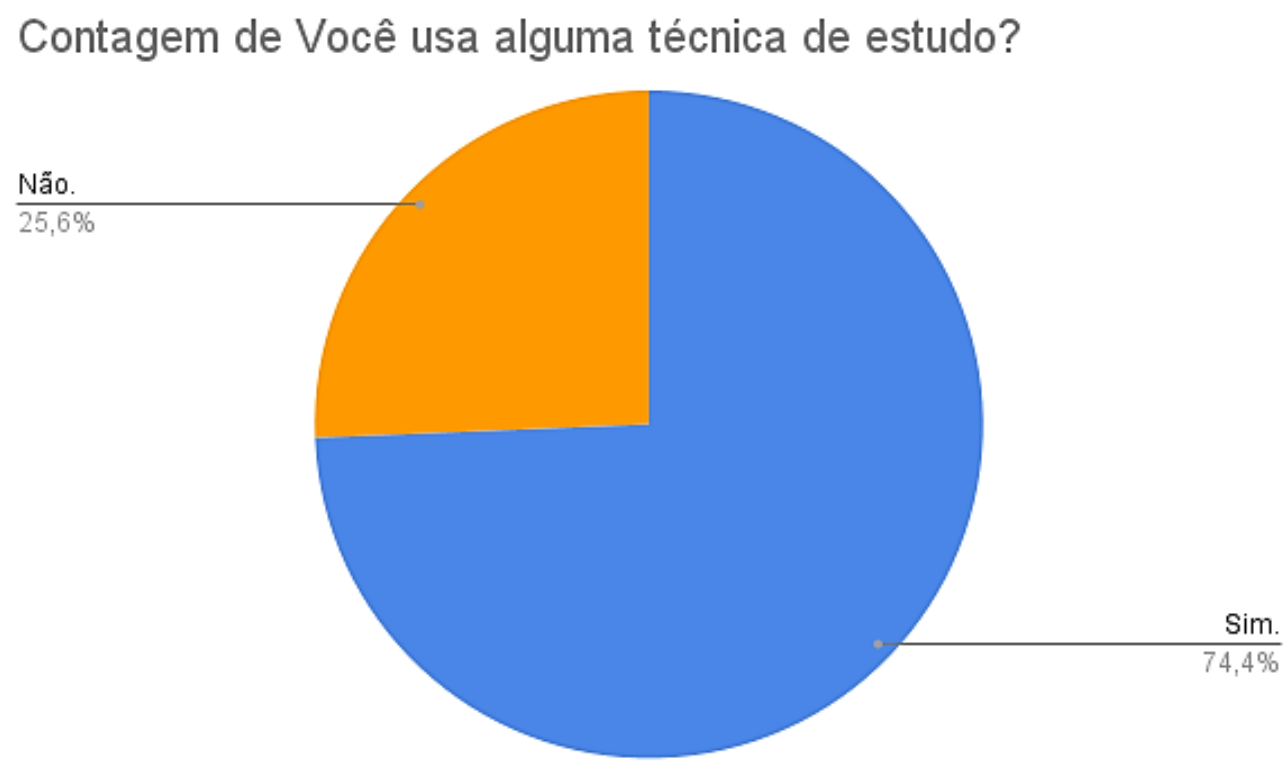

Fonte: Os autores (2021)

A figura a seguir traz o resultado das técnicas de estudos usados pelos discentes:

Figura 17 - Tipos de técnicas de estudo 
Contagem de Se marcou "Sim" para resposta anterior, marque abaixo qu...

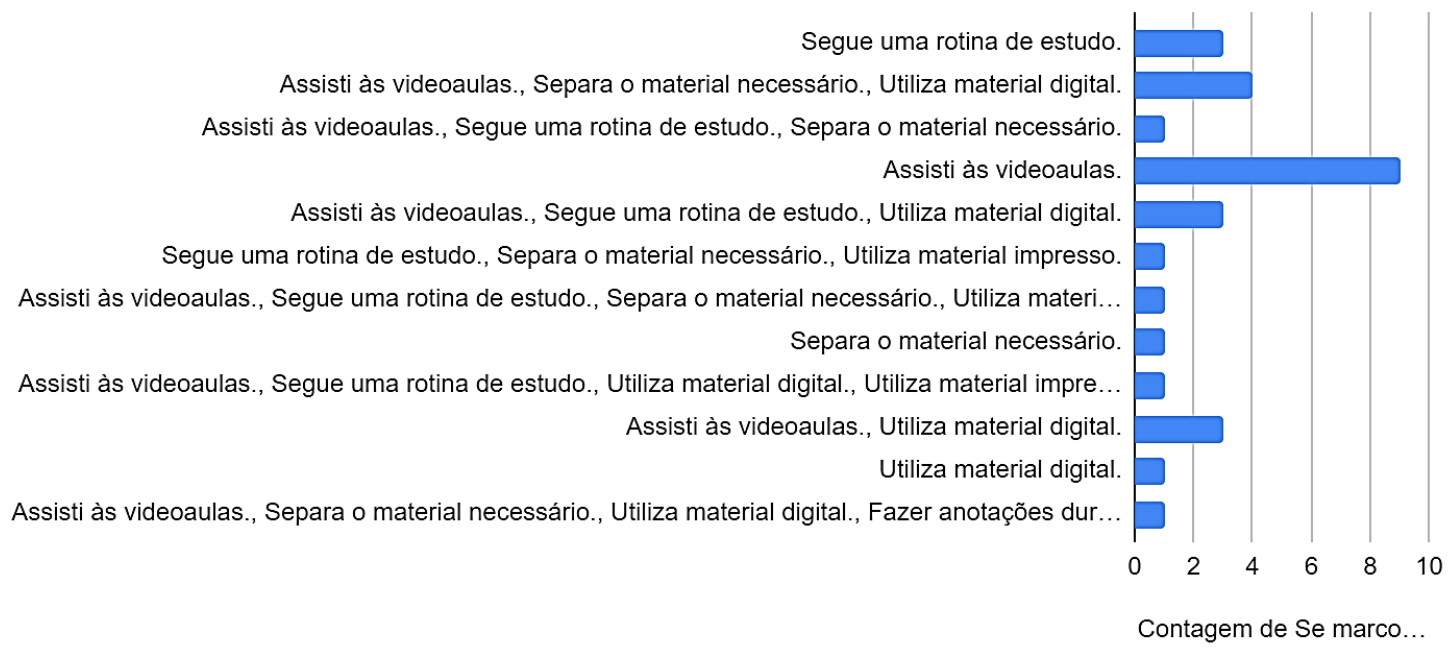

Fonte: Os autores (2021)

A questão financeira é um ponto importante a ser destacado pois a maioria, ou seja, cerca de $74 \%$ são de classes mais baixas, por isso alguns precisaram arrumar um emprego para ajudar financeiramente a família. Muitos deles desistem por não conseguir, outros tem uma queda no desempenho, mas segue nos estudos.

Figura 18 - Classe econômica

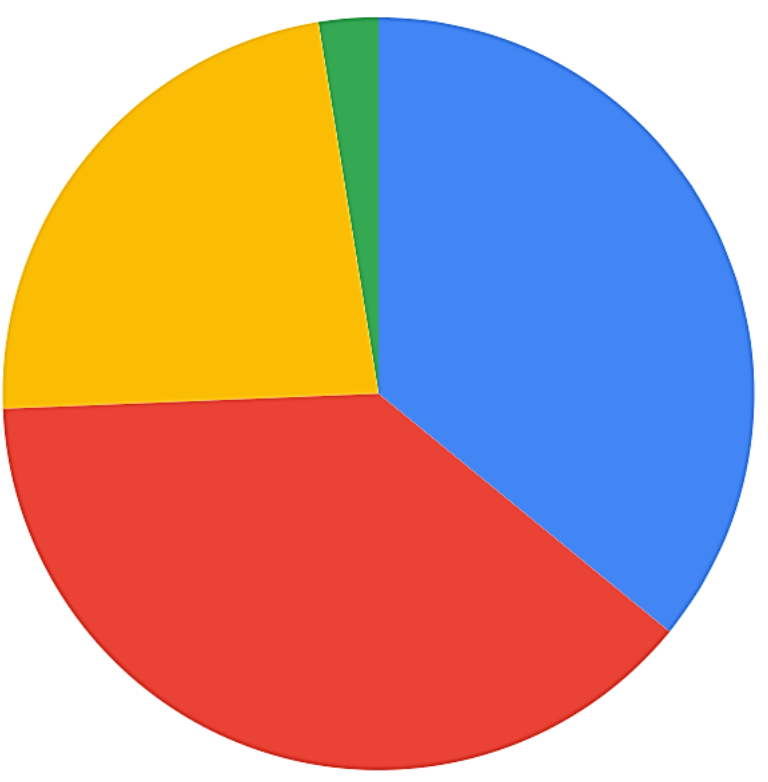

Classe C (De R\$ 2005 até $R \$ 8640)$.

Classe E (De R\$ 0 até R\$ 1254).

Classe D (De R\$ 1255 até R\$ 2004).

Classe B (De R\$ 8461 até $R \$ 11261)$.

Fonte: Os autores (2021)

Figura 19 - Atividades financeiras 


\section{Contagem de Você realizou alguma atividade cujo recompensa fosse financeira para ajudar em casa?}

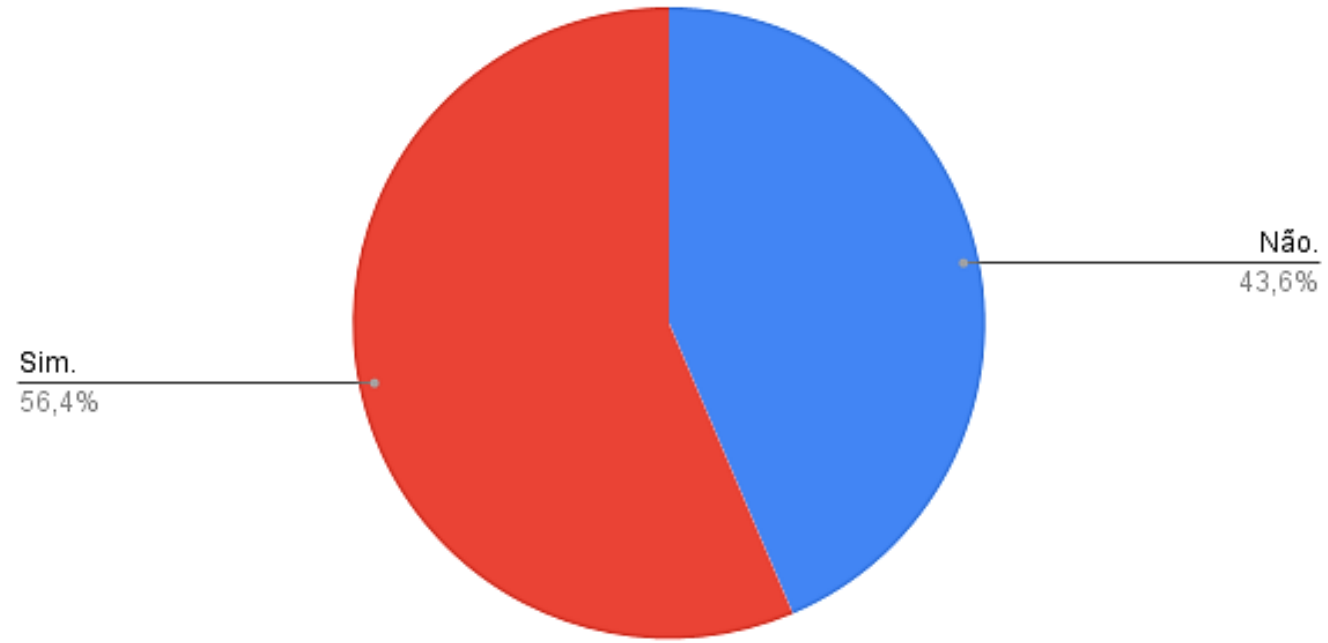

Fonte: Os autores (2021)

\section{CONCLUSÃO}

A rede de educação está com suas atividades escolares presenciais suspensas, atingindo milhões de estudantes em todo o país. Contudo, a educação não deve parar, afim de analisar essa situação foi feita pesquisa com o uso de formulários através do Google Form.

Os resultados desvelados pela pesquisa apontam que, estudantes, e instituições educativas não estavam preparados para se adaptar a essa nova modalidade de ensino, que obrigou a sociedade a adotar o uso de ferramentas tecnológicas para se adaptar ao sistema de ensino remoto.

A pesquisa mostra e recomenda outras maneiras de organizar o ensino pegando pontos importantes para não cometer os mesmos erros, tal realidade exige um novo modo de trabalho docente e discente, o uso de ferramentas e manuseio de tecnologias de vídeo, a implantação de novas metodologias didáticas, demandando novas rotinas de adaptação. A pesquisa revelou que o ensino remoto proporcionou pouco aprendizado aos alunos, assim considerando o ensino presencial mais eficaz na aprendizagem.

As escolas constataram ou estão pelo menos seguindo para esse caminho de estudo a distância, onde é/foi preciso treinar e desenvolver técnicas para melhor prática das funções no ensino remoto. Ao longo desse estudo percebe-se que as plataformas digitais (assíncronas e síncronas) são de grandes importâncias nesse tempo de isolamento social. 
O WhatsApp, o Meet ou o Zoom, além de serem os mais utilizados para passar conteúdos, existem outras formas de comunicação mais capacitados para uso pedagógico, como o Discord por ter vídeo chamada limitada para as aulas síncronas e funciona como um mensageiro, 2 em 1 se for comparando com WhatsApp e Meet. Outra aplicação mais favorável é o Telegram como forma de substituir o WhatsApp.

De acordo com a pesquisa, 30 dos 39 discentes têm aparelho celular, um dispositivo essencial para o uso do WhatsApp, pois necessitam restritivamente de um smartphone para funciona. Então os aplicativos mencionados acima resolvem esse problema, pois não precisam necessariamente de um smartphone para serem usados.

Diante desta visão, o presente trabalho teve como objetivo mostrar formas de melhorar o ensino EaD (Educação a Distância) usando tecnologias, como os aplicativos de mensagem instantânea (Discord e Telegram) é suas potencialidades pedagógicas para o ensino remoto. Considera-se que o objetivo geral foi atingido, pois diante de todas as análises, pôde-se de fato conhecer e sugerir algumas ações que poderão trazer diversas melhorias na escola com outras formas de aplicações.

\section{REFERÊNCIAS}

ALMEIDA, E. B., BORGER, M., \& FRANÇA, G. (2012). O uso das tecnologias móveis na escola: uma nova forma de organização do trabalho pedagógico. $X V I$ ENDIPE-Encontro Nacional de Didática e Práticas de Ensino, UNICAMP-Campinas, 2012.

ALMEIDA, M. E. B., \& VALENTE, J. A. (2012). Integração currículo e tecnologias e a produção de narrativas digitais. Currículo sem fronteiras, 12(3), 57-82.

ANDRADE CARNEIRO, L., PRATA, D. N., MOREIRA, P. L., \& BARBOSA, G. V. (2019). Collaborative Learning in the Military Police of Tocantins: perspective without frontier. International Journal of Advanced Engineering Research and Science, 6(7).

Comissão de Estudos Sobre a Implantação de atividades Remotas no IFPA, Campus Tucuruí (CERAE). O contexto da Pandemia para o Desenvolvimento das Atividades do IFPA Campus Tucuruí: Epidemiologia da região, acessibildade à tecnologias remotas e atividades presenciais e saúde física e mental dos servidores, dos terceirizados e estudantes do IFPA, Campus Tucuruí. Tucuruí - PA, 2020.

COELHO, Beatriz. Metodologia científica: aprenda como delimitar na sua pesquisa. Blog Mettzer, Ago. de 2020 Disponível em:

https://blog.mettzer.com/metodologia-cientifica/amp/. Acesso em: 16 de nov. de 2021. 
DINO. Profissional cita razões para usar o Telegram na estratégia de marketing digital. Terra, 16 de nov. de 2020. Disponível em: <

https://www.terra.com.br/noticias/dino/profissional-cita-razoes-para-usar-o-telegramna-estrategia-de-marketing-

digital,4c992eb01f8b4706d7fa7b655f92d897rfe1wug3.html>. Acesso em 28 de jul. de 2021.

IBGE. Pesquisa mostra que 82,7\% dos domicílios brasileiros têm acesso à internet. 14 de abril de 2021 Disponível em: https://www.gov.br/mcom/pt-

br/noticias/2021/abril/pesquisa-mostra-que-82-7-dos-domicilios-brasileiros-tem-acessoa-internet. Último acesso em 23 de jul. de 2021.

LOPES, Adriana. Educa Mais Brasil. Geografia Econômica. 28 de set. de 2018. Disponível em: https://www.educamaisbrasil.com.br/enem/geografia/geografiaeconomica. Último acesso em 25 de jul. de 2021.

LUIZ, Robson. Brasil Escola. Matemática: Estatística. s.d. Disponível em: < https://brasilescola.uol.com.br/matematica/estatistica-2.htm>. Último acesso em 25 de jul. de 2021.

OLIVEIRA, Elida. Quase 90\% dos professores não tinham experiência com aulas remotas antes da pandemia; $42 \%$ seguem sem treinamento, aponta pesquisa. G1, Salvador, 08 de jul. de 2020. Disponível em: <

https://g1.globo.com/educacao/noticia/2020/07/08/quase-90percent-dos-professoresnao-tinham-experiencia-com-aulas-remotas-antes-da-pandemia-42percent-seguem-semtreinamento-aponta-pesquisa.ghtml>. Acesso em: 16 de nov. de 2021.

SANTAELLA, L. (2013). Desafios da ubiquidade para a educação. Revista Ensino Superior Unicamp, 9, 19-28.

SANTOS, Thamires. Educa Mais Brasil. Classe Social. 14 de out. de 2020. Disponível em: https://www.educamaisbrasil.com.br/enem/sociologia/classe-social. Último acesso em 25 de jul. de 2021.

Suporte Discord. Chamadas de Vídeo. Disponível em: https://support.discord.com/hc/pt-br/articles/360041721052-Chamadas-deV\%C3\%ADdeo. Acesso em: 25 de jul. de 2021.

Telegram. Página inicial do Telegram. Disponível em: <https://telegram.org/> Acesso em 25 de nov. de 2021.

WILDER-SMITH, A., \& FREEDMAN, D. O. (2020). Isolation, quarantine, social distancing and community containment: pivotal role for old-style public health measures in the novel coronavirus (2019-nCoV) outbreak. Journal of travel medicine, 27(2), taaa020. 